\title{
Retrieval-induced forgetting of multiplication facts and identity rule
}

\author{
Jamie I. D. Campbell • Kate D. Dufour • Yalin Chen
}

Published online: 13 November 2014

(C) Psychonomic Society, Inc. 2014

\begin{abstract}
This research investigated retrieval-induced interference between counterpart multiplication $(2 \times 3=6)$ and addition facts $(2+3=5)$. Adults $(\mathrm{N}=72)$ repeatedly solved either a set of simple addition $(0+2,1+5,2+3)$ or multiplication problems $(0 \times 2,1 \times 5,2 \times 3)$ during a practice phase and then switched operations during a test phase that included counterparts to the practiced problems and control problems. The paradigm afforded measurement in response time both of inter-operation retrieval-induced forgetting (RIF) and generalization of practice across different problems within operations. The experiment demonstrated generalization of practice for the rule-based $0+\mathrm{N}=\mathrm{N}$ problems (e.g., practicing $0+2$ facilitated performance on $0+7$ ) as well as for problems governed by the multiplicative identity principle $(1 \times \mathrm{N}=\mathrm{N})$ and zero-product principle $(0 \times \mathrm{N}=0)$, but not the fact-based 1 $+\mathrm{N}$ problems. The experiment also demonstrated for the first time inter-operation RIF of fact-based multiplication, which was as large as the effect observed for fact-based addition. The $0 \times \mathrm{N}, 0+\mathrm{N}$, and $1+\mathrm{N}$ problems did not present item-specific RIF from practice of cross-operation counterparts, but $1 \times \mathrm{N}$ problems did, despite the generalization-of-practice evidence that $1 \times \mathrm{N}$ problems were solved using an item-general procedure. The item-specific RIF for $1 \times \mathrm{N}=\mathrm{N}$ must reflect itemspecific interference rather than item-level competitor inhibition given that there is no item-level representation of $1 \times \mathrm{N}=$ $\mathrm{N}$ facts in long-term memory.
\end{abstract}

Keywords Mathematical cognition $\cdot$ Retrieval-induced forgetting $\cdot$ Addition $\cdot$ Multiplication $\cdot$ Procedure

J. I. D. Campbell $(\bowtie) \cdot$ K. D. Dufour · Y. Chen

Department of Psychology, University of Saskatchewan, 9 Campus

Drive, Saskatoon, SK, Canada S7N 5A5

e-mail: jamie.campbell@usask.ca
Every school child knows that arithmetic involves facts (e.g., $1+2=3)$ and rules $(1 \times 2=2,0 \times 2=0)$, the latter corresponding to elementary algebraic principles. The present research concerned adults' memory processes underlying instantiation of the multiplicative identity principle $(1 \times \mathrm{N}=\mathrm{N})$, zero-product principle $(0 \times \mathrm{N}=0)$, and the additive identity principle $(0+\mathrm{N}=\mathrm{N})$. Research has consistently indicated that the rule-governed zero and one problems are normally solved by applying the appropriate rule rather than by retrieval of individually stored facts in memory. The research supporting this view includes behavioral (Butterworth, Zorzi, Girelli \& Jonkheere, 2001; Campbell \& Metcalfe, 2007; LeFevre, Bisanz, Daley, Buffone, Greenham \& Sadesky, 1996), imaging (Jost, Beinhoff, Hennighausen \& Rösler, 2004), and neuropsychological evidence (Pesenti, Depoorter \& Seron, 2000; Sokol, McCloskey, Cohen, \& Aliminosa, 1991).

Of central interest here is the phenomenon of retrievalinduced forgetting (RIF) and performance of fact-retrieval based and rule-based arithmetic. Repeated retrieval practice of a memory item can impair retrieval of related, unpracticed items (Anderson, Bjork \& Bjork, 1994). RIF is observed in a wide variety of memory domains (e.g., Anderson, 2003; Storm \& Levy, 2012) including memory for basic addition facts (Campbell \& Thompson, 2012a). The addition RIF research uses a version of the standard RIF retrieval-practice paradigm (Anderson, 2003) in which participants repeatedly practice a set of multiplication problems (e.g., $2 \times 5,3 \times 3$, etc.) and then are tested on the addition counterparts (i.e., $2+$ $5,3+3)$ and control addition problems. Several experiments have shown that multiplication practice slows response time (RT) or increases errors for the counterpart addition problems (e.g., Campbell, Chen \& Maslany, 2013; Campbell \& Dowd, 2012; Campbell \& Thompson, 2012a). In the RIF literature broadly the effect is usually measured as failures of recall. Applying the term RIF to reduced memory accessibility without memory failure (expressed in longer retrieval times, for 
example) implies a continuum of RIF that ranges from weakened memory strength or efficiency to more complete forgetting in which the desired memory is inaccessible.

Campbell and Therriault (2013) proposed that the addition RIF effect is potentially diagnostic of specific instances of $0 \times$ $\mathrm{N}=0$ and $1 \times \mathrm{N}=\mathrm{N}$ problems stored in memory. RIF is most likely to occur for memory items that are competitors of the target memory (Anderson, 2003; Levy, McVeigh, Marful \& Anderson, 2007; Norman, Newman \& Detre, 2007; but see Jakab \& Raaijmakers, 2009). This competition dependence of RIF (see Storm \& Levy, 2012, for a recent review) would explain why Campbell and Thompson (2012a; Campbell et al., 2013) observed RIF of small addition problems with sums $\leq 10$ (e.g., $2+4,3+5$ ) following the practice of multiplication counterparts, but larger additions (e.g., $7+9,6+8$ ) did not present RIF. This implies competition dependency because small addition facts have high memory strength and would be strong competitors for their multiplication counterparts whereas the relatively weaker memory for large addition facts would not (Campbell \& Thompson, 2012a). If RIF of addition is competition dependent, we would not expect RIF for the addition counterparts of the $0 \times \mathrm{N}=0$ and $1 \times \mathrm{N}=\mathrm{N}$ problems because answering $0 \times \mathrm{N}$ and $1 \times \mathrm{N}$ problems by reference to their respective rules would not encounter competition from addition counterparts at the item level. Such itemlevel competition would occur only when there are fact-based representations for both multiplication and addition counterparts. Campbell and Therriault found the usual RIF effect of multiplication practice on subsequent performance of addition facts with sums $\leq 10($ e.g., $2+3$ ) but practicing $0 \times \mathrm{N}$ and $1 \times \mathrm{N}$ multiplication problems did not yield RIF of the addition counterpart $0+\mathrm{N}$ or $1+\mathrm{N}$ problems. This result reinforces the theory that rule-based and fact-based multiplication are mediated by different types of memory processes and that arithmetic RIF requires item-level retrieval competition.

\section{The present experiment}

RIF of addition fact memory from practice of multiplication counterparts is a robust phenomenon, but no research has examined RIF in the other direction; that is, RIF of multiplication by practice of the addition counterparts. The previous research focused on measuring RIF with multiplication practice followed by an addition test because a variety of findings had demonstrated an asymmetry whereby multiplication interfered with addition more than addition interfered with multiplication (Campbell \& Arbuthnott, 2010; Miller \& Paredes, 1990; Zbrodoff \& Logan, 1986). For example, RT costs on answering simple addition and multiplication problems in mixed-operation blocks, relative to single-operation blocks, are greater for addition than for multiplication. These effects are observed in adults' performance, but Miller and
Paredes (1990) proposed that the asymmetry in interference between addition and multiplication is a relic of early learning. Addition is learned before multiplication, and the subsequent learning of multiplication therefore requires suppression of addition. This creates a permanent asymmetry in the extent of mutual retrieval interference between the operations. One purpose of the present research was to determine if this asymmetry extended to the RIF paradigm. In this case, an asymmetrical mixture effect in mixed addition and multiplication blocks could arise, in part, from asymmetrical RIF.

The other purpose was to complete the taxonomy of practice-test combinations of fact-based and rule-based addition and multiplication counterpart problems using the RIF paradigm. Table 1 presents this taxonomy and also the predictions for RIF based on the assumption that RIF will only occur when both the practiced items and test items are answered by retrieval of individual facts and the test item is a strong competitive memory for the target item (Campbell \& Therriault, 2013). When multiplication was practiced followed by an addition test, we expected to replicate Campbell and Therriault. Specifically, RIF will only occur when both practice and test conditions are fact based and not when either is rule based. By extension, we expected the same pattern when addition was practiced followed by a multiplication test, unless the previously discussed asymmetry in inter-operation interference favoring multiplication is so complete that no RIF is observed in any multiplication test condition.

The design of the experiment also afforded measurement of generalization of practice across different problems within operations. Because procedures are assumed to be algorithms applicable to any appropriate problem, improving the efficiency of the procedure through practice of one set of problems should generalize to other problems (Singley \& Anderson, 1989). Consequently, generalization effects provide a converging diagnostic test for procedure-based versus factretrieval based arithmetic. Campbell and Beech (2014) examined simple addition for evidence of generalization for factbased additions and also addition with zero, which is governed by the additive identity rule (e.g., $0+8=8$ ). The procedurebased $0+\mathrm{N}=\mathrm{N}$ problems presented evidence of generalization (i.e., practicing a subset of $0+\mathrm{N}$ problems facilitated a different subset of $0+\mathrm{N}$ problems), but there was no evidence of such generalization for the non-zero problems (see also Campbell \& Therriault, 2013). The present experiment afforded the first examination of generalization of practice for all three rule-governed problem types of addition and multiplication (i.e., $0+\mathrm{N}=\mathrm{N}, 1 \times \mathrm{N}=\mathrm{N}$, and $0 \times \mathrm{N}=0$ ).

\section{Method}

Participants Seventy-two volunteers participated for bonus marks in their introductory psychology course at the 
Table 1 Predictions for RIF of arithmetic problems following practice of operation counterparts

\begin{tabular}{lll}
\hline Practice & Test & Item-specific RIF \\
\hline $\begin{array}{l}\text { Fact-based multiplication } \\
(\mathrm{M} \times \mathrm{N}=?)\end{array}$ & $\begin{array}{l}\text { Fact-based addition } \\
(\mathrm{M}+\mathrm{N}=?)\end{array}$ & Yes, if competitive \\
$\begin{array}{l}\text { Rule-based } \\
\text { multiplication }\end{array}$ & Fact-based addition & No \\
$(1 \times \mathrm{N}=\mathrm{N})$ & $(1+\mathrm{N}=?)$ & \\
$\begin{array}{l}\text { Rule-based } \\
\text { multiplication }\end{array}$ & Rule-based addition & No \\
$(0 \times \mathrm{N}=0)$ & $(0+\mathrm{N}=\mathrm{N})$ & \\
$\begin{array}{l}\text { Fact-based addition } \\
(\mathrm{M}+\mathrm{N}=?)\end{array}$ & $\begin{array}{l}\text { Fact-based multiplication } \\
(\mathrm{M} \times \mathrm{N}=?)\end{array}$ & Yes, if competitive \\
$\begin{array}{l}\text { Rule-based addition } \\
(0+\mathrm{N}=\mathrm{N})\end{array}$ & $\begin{array}{l}\text { Fact-based multiplication } \\
(0 \times \mathrm{N}=0)\end{array}$ & No \\
$\begin{array}{l}\text { Fact-based addition } \\
\text { Rule-based }\end{array}$ & No \\
$(1+\mathrm{N}=?)$ & $\begin{array}{l}\text { multiplication } \\
(1 \times \mathrm{N}=\mathrm{N})\end{array}$ & \\
\hline
\end{tabular}

Note. In the stimuli, $\mathrm{M}$ and $\mathrm{N}$ are single-digit operands $\geq 2$. RIF $=$ retrieval-induced forgetting

University of Saskatchewan. None had participated in previous arithmetic RIF studies. Alternating participants were assigned to the addition practice/multiplication test or multiplication practice/addition test groups. In the former group, there were 23 women and 13 men, aged 17-26 years $(M$ $=19.5$ ), of whom 34 were right-handed and two were lefthanded. Twenty-eight reported English as their first language for arithmetic, three reported Spanish, and one each reported Chinese, Cantonese, Mandarin, Turkish, and Tagalog. For the latter group, there were 26 women and ten men, aged 16-28 years $(M=18.9)$, all right-handed. Thirty-four reported English as their first language for arithmetic and one each reported Chinese and Korean. All participants answered the arithmetic problems in English.

Apparatus Stimuli were presented on two CRT monitors using Eprime 2.0 (Psychology Software Tools, Pittsburgh, PA, USA) with one monitor viewed by the participant and the other by the experimenter. The participant sat about $50 \mathrm{~cm}$ from the monitor and held a microphone connected to the computer through Eprime's SRbox. Detection of the participant's verbal response by the microphone provided response time accuracy to within $\pm 1 \mathrm{~ms}$.

Stimuli and design The stimuli and design were identical to Campbell and Therriault (2013) and the group that had multiplication practice followed by addition test constituted a replication of that study. For the other group, the experiment was the same except that they received addition practice followed by multiplication test. Stimuli appeared in black Courier New 14 font on a white background. Problems occupied five horizontal character spaces and appeared with the smaller operand on the left (e.g., $0+2)$. Addition and multiplication problems were created from the 32 pairs of singledigit numbers that sum to ten or less, excluding pairs comprised of only 0 and/or 1 . Sixteen pairs corresponded to rulerelated problems and 16 corresponded to fact-based problems. The rule-related pairs were divided into two sets of eight $(03$ 04050812161719 and 02060709131415 18). Each set contained four 0-related and four 1-related pairs, with 0 and 1 each combined with two odd and two even numbers in the range 2-9. Note that the $0+\mathrm{N}=\mathrm{N}, 0 \times \mathrm{N}=0$, and $1 \times \mathrm{N}=\mathrm{N}$ problems are rule governed, but the $1+\mathrm{N}=$ ? problems are not because their solution does not correspond to one of the presented operands. They may be considered rule-related, however, because Campbell and Metcalfe (2007) found rule intrusions to be the most common error type for these items (i.e., $1+\mathrm{N}=\mathrm{N}$ ). The fact-based pairs were also divided into two sets of eight (2425272833 344655 and 2223263536 3744 45). Each set included two "tie" pairs (e.g., 33, 44).

A rule-related and fact-based set were combined to make the practice set of 16 pairs and the other two sets were combined for the unpracticed set. The four combinations of rule-related and fact-based sets for the practice phase were counterbalanced over four consecutive participants within each group. In the practice phase, participants received four blocks of the practice set of 16 problems (either multiplication or addition). For the test phase, participants received two blocks of 32 problems in the other, unpracticed operation. Following Campbell and Therriault (2013), no operation sign was presented during the test phase so that the problem stimulus did not explicitly identify the required operation. This might increase the opportunity to observe RIF from practice of the competing operation. The order of problems in both the practice and test phases was independently randomized for each participant.

Procedure The 30-min experiment took place in a quiet testing room with an experimenter present. Prior to the arithmetic task, microphone sensitivity was tested by asking participants to quickly name eight single letters $a$ though $h$ presented sequentially at the centre of the screen in random order in Courier New 14 font. The arithmetic practice phase comprised four blocks of 16 trials. Participants were asked to state the correct answer aloud for each problem with an emphasis on accuracy. The test phase consisted of two blocks of 32 problems in the unpracticed operation, including both the operation-counterpart practiced and unpracticed sets. Participants were instructed to state the sum or product of the digit pair that appeared on each trial as quickly as possible.

Each trial began with a central fixation dot for $1 \mathrm{~s}$ followed by the problem centered at fixation. Response timing began when the problem appeared and continued until the participant's verbal response stopped the timer. When the response was detected, the problem immediately disappeared from the 
screen. This allowed the experimenter to identify failures of the microphone to detect response onset and flag those RTs for exclusion. The experimenter entered the participant's answer and then the fixation dot appeared to signal the beginning of the next trial. No feedback regarding speed or accuracy was provided during either the practice or test phase.

\section{Results}

ANOVA tests had $F(1,70)$ degrees of freedom unless otherwise indicated. We analyzed median RT owing to the relatively small number of observations per cell (Miller, 1988).

Practice phase A total of 15 practice RTs $(0.7 \%)$ were marked for exclusion by the experimenter. The error rate during multiplication practice was $0.7 \%$ with a total of 15 errors, too few for a systematic analysis. Median RT for correct responses received an Operation (addition vs. multiplication $) \times$ Problem type $($ fact based vs. rule related $) \times$ Block ( 1 and 2 vs. 3 and 4) ANOVA with operation as a betweenparticipants factor and problem type and block as repeated measures. The corresponding means appear in Fig. 1 with $95 \%$ repeated-measures confidence intervals based on the MSE for the three-way interaction (Jarmasz \& Hollands, 2009; Masson \& Loftus, 2003). ${ }^{1}$

Overall, mean median addition RT ( $666 \mathrm{~ms})$ was faster than multiplication RT $(736 \mathrm{~ms})[F=5.42, p=.023, M S E$ $\left.=66033.28, \eta_{\mathrm{p}}^{2}=.072\right]$. All other main and interaction effects were also significant with $p \leq .002$. As the pattern of differences is apparent from the means and confidence intervals in Fig. 1 we do not report all the ANOVA tests in detail $[F=9.98$, $p=.002, M S E=1086.08, \eta_{\mathrm{p}}^{2}=.125$ for the three-way interaction]. As Campbell and Therriault (2013) observed, rule-related problems $(649 \mathrm{~ms})$ were answered more quickly than fact-based problems $(753 \mathrm{~ms})$ and participants responded more quickly later in practice $(673 \mathrm{~ms})$ than earlier in practice (729 ms). As Fig. 1 shows, the amount of speed-up was approximately proportional to the mean RT early in practice (i.e., Blocks 1 and 2). Proportional speed-up would occur primarily because the faster problem types were closer to their speed-up asymptote from the outset of the experiment, which would limit their RT gains from practice. The fact-based multiplication problems were clearly the slowest problem type early in practice, and sped up the most; consequently, proportional speed-up produced the three-way interaction shown in Fig. 1.

\footnotetext{
${ }^{1}$ The confidence intervals, effect size and Bayes Factor values reported in this article were calculated using MorePower 6.0 (Campbell \& Thompson, 2012b). MorePower 6.0 is freely available at https://wiki.usask.ca/ pages/viewpageattachments.action?pageId $=420413544$.
}

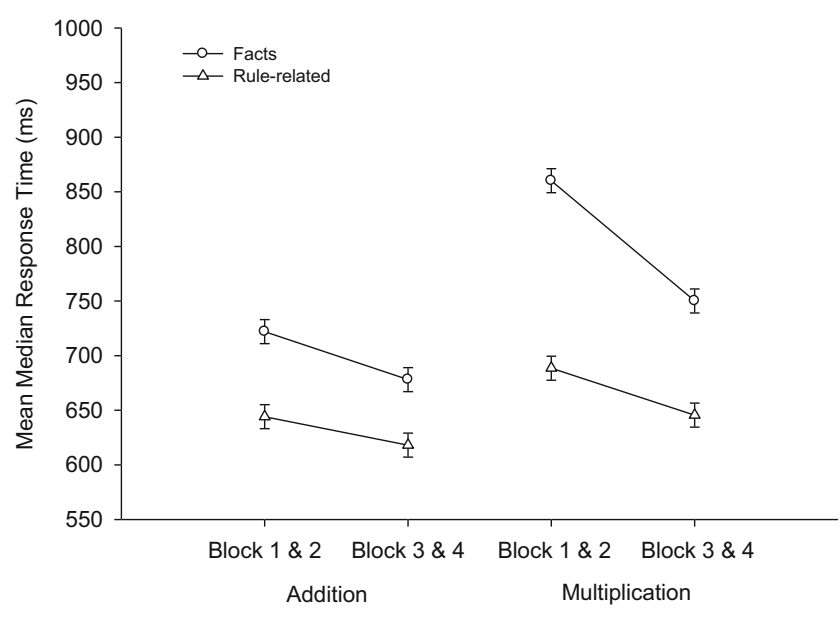

Fig. 1 Mean multiplication and addition response time during the practice phase. Facts $=$ fact-based problems. Rule-related $=$ both $0 \times \mathrm{N}$ and $1 \times$ $\mathrm{N}$ for multiplication and both $0+\mathrm{N}$ and $1+\mathrm{N}$ for addition. Error bars are $95 \%$ repeated-measures confidence intervals based on the MSE for the Operation $\times$ Problem type $\times$ Block interaction

Median RT for the 0 and 1 problems received a separate Operation $\times$ Problem type ( 0 vs. 1$) \times$ Blocks $(1$ and 2 vs. 3 and 4) ANOVA (see Fig. 2 for the corresponding means and $95 \%$ confidence intervals based on the MSE for the three-way interaction). Again, as the pattern of differences is apparent from the means and confidence intervals we do not report all the ANOVA tests in detail $[F=8.44, p=.005, M S E=1226.23$, $\eta_{\mathrm{p}}^{2}=.11$ for the three-way interaction]. For addition, the rulebased $0+\mathrm{N}$ problems were answered more quickly $(587 \mathrm{~ms})$ than the $1+\mathrm{N}$ problems $(682 \mathrm{~ms})$, which were more similar in mean response time to the other fact-based addition problems (700 ms). For multiplication, the mean RT for $0 \times \mathrm{N}$ problems was 49 ms slower than $1 \times \mathrm{N}$ in Block 1 , but this difference was largely eliminated in Block 2 . The greater speed-up for 0 $\times \mathrm{N}$ compared to the other three rule-related problem types produced the three-way interaction. The relatively small amount of speed-up for $1+\mathrm{N}$ problems, despite being the slowest of the rule-related problem types overall, appears to violate the general observation that speed-up was proportional to mean RT early in practice. As we show in the subsequent test phase analyses, however, among the rule-related problems only the $1+\mathrm{N}$ problems did not benefit from generalization of practice across different instances (i.e., practicing $0+3$ benefited subsequent performance of $0+5$, but practicing 1 +3 did not facilitate subsequent performance of $1+5$ ) (see also Campbell \& Beech, 2014). This absence of generalization would limit speed-up for the $1+\mathrm{N}$ problems.

Test phase A total of 119 test phase RTs (5.2\%) were marked as spoiled by the experimenter. There were 43 errors committed on fact-based problems ( $3.7 \%$ of trials) and 21 errors on the rule-related problems $(0.9 \%$ of trials $)$, too few for a meaningful factorial analysis. Twenty of the 21 rule-related errors were consistent with rule confusions or intrusions (e.g., 


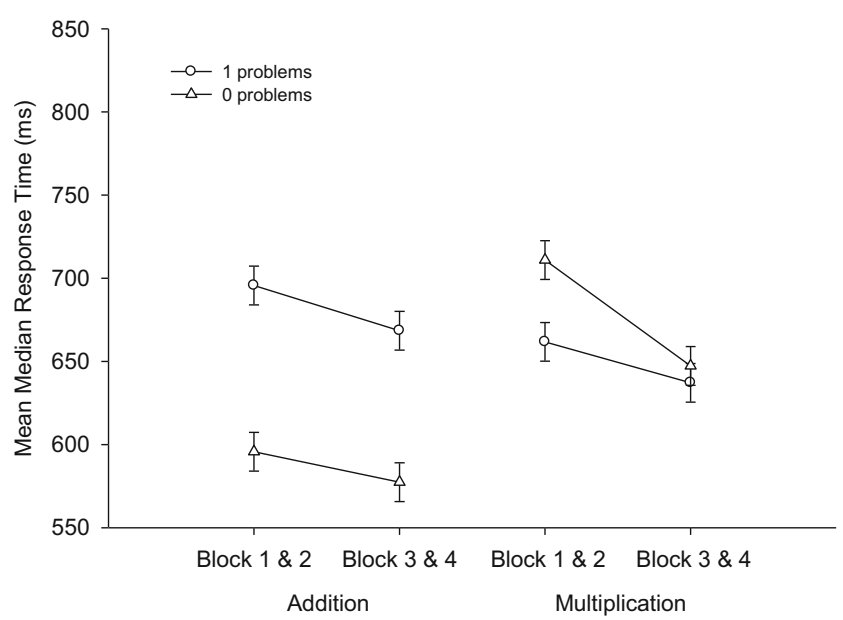

Fig. 2 Mean multiplication and addition response time for 0 and 1 problems during the practice phase. Error bars are $95 \%$ repeatedmeasures confidence intervals based on the MSE for the Operation $\times$ Problem type $\times$ Block interaction

$0 \times \mathrm{N}=\mathrm{N}, 1+\mathrm{N}=\mathrm{N})$. Median RT for correct answers received an Operation (multiplication vs. addition) $\times$ Problem type (rule-related vs. facts) $\times$ Practice Set (operation-counterpart practiced vs. unpracticed) $\times$ Block (1 vs. 2) mixed-factor ANOVA. The corresponding mean RTs appear in Fig. 3. Error bars are $95 \%$ repeated-measures confidence intervals based the MSE for the Problem type $\times$ Practice Set $\times$ Block interaction.

Fact-based problems had a slower mean RT $(855 \mathrm{~ms})$ than rule-related problems (688 ms) $[F=174.87, p<.001, M S E$ $\left.=22952.79, \eta_{\mathrm{p}}^{2}=.71\right]$ and RT sped up from Block $1(810 \mathrm{~ms})$ to Block 2 (734 ms) $\left[F=98.94, p<.001, M S E=8461.00, \eta_{\mathrm{p}}^{2}\right.$ $=.59]$. As Fig. 3 shows, the amount of speed-up across blocks was approximately proportional to Block 1 RT, which produced an Operation $\times$ Problem type $\times$ Block interaction $[F$ $\left.=7.64, p=.007, M S E=4142.79, \eta_{\mathrm{p}}^{2}=.10\right]$. With respect to RIF, problems whose other-operation counterpart had been practiced were answered slower on average $(785 \mathrm{~ms})$ than counterpart-unpracticed problems (758 ms) $[F=13.86, p<$ $\left..001, M S E=7349.17, \eta_{\mathrm{p}}^{2}=.17\right]$, but this overall RIF effect was greater for fact-based problems [46 ms, $t(71)=4.08, p=.0001$, $\mathrm{SE}=11.31]$ than rule-related problems $[7 \mathrm{~ms}, t(71)=0.97, p=$ $.334, \mathrm{SE}=7.19]\left[F=9.90, p=.002, M S E=5585.53, \eta_{\mathrm{p}}^{2}=.12\right.$ for the Problem type $\times$ Practice Set interaction]. ${ }^{2}$ There was no evidence that this effect differed between operations $(p=.97$

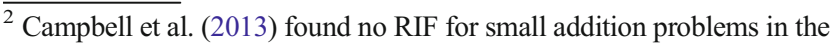
Chinese participants they tested. In the present study, there was one Chinese participant in the addition test group. The RIF results were the same whether or not this participant's data (a 66-ms difference in the direction of RIF for fact-based addition) were included in the analysis. Also, the pattern of RIF effects was the same when data only from the 62 participants who reported English as their first language for arithmetic were included for analysis.
}

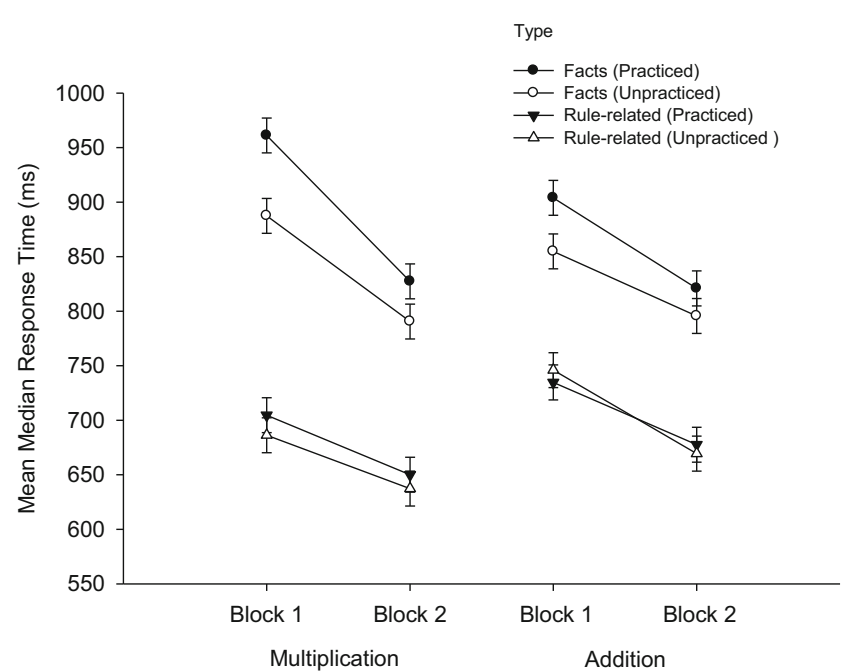

Fig. 3 Mean multiplication and addition response time during the test phase. Facts $=$ fact-based problems. Rule-related $=$ both $0 \times \mathrm{N}$ and $1 \times \mathrm{N}$ for multiplication and both $0+\mathrm{N}$ and $1+\mathrm{N}$ for addition. Error bars are $95 \%$ repeated-measures confidence intervals based on the MSE for the Problem type $\times$ Practice Set $\times$ Block interaction

for the Operation $\times$ Problem type $\times$ Practice Set interaction and $p=.79$ for the four-way interaction).

Nonetheless, because the finding of RIF of fact-based multiplication problems by practice of their addition counterparts is a new finding, it is important to confirm this effect separately. The observed RIF for fact-based multiplication was $74 \mathrm{~ms}$ in Block $1[t(35)=2.81, p=$ $.008, \mathrm{SE}=26.18]$ and $37 \mathrm{~ms}$ in Block $2[t(35)=2.38, p$ $=.02, \mathrm{SE}=15.48]$. A relatively conservative BIC-based Bayesian hypothesis test (Campbell \& Thompson, 2012b; Masson, 2011) of the overall $55 \mathrm{~ms}$ RIF effect $(\mathrm{SE}=16.79)$ for fact-based multiplication yielded a Bayes Factor of .047 , indicating that the data provided strong evidence for the effect. Thus, the RIF effect for fact-based multiplication was robust and Fig. 2 shows the effect was at least as large as the well established RIF effect observed for addition here (49 $\mathrm{ms}$ and $25 \mathrm{~ms}$ in Blocks 1 and 2, respectively) and in several previous experiments (e.g., Campbell \& Therriault, 2013; Campbell \& Thompson, 2012a).

To directly compare the 0 and 1 rule-related problems, median RT for the rule-related problems received an Operation (multiplication vs. addition) $\times$ Problem type $(0$ vs. 1$) \times$ Practice Set (operation-counterpart practiced vs. unpracticed) $\times$ Block (1 vs. 2) ANOVA. Means for the 0 and 1 rule-related problems appear in Fig. 4 with $95 \%$ repeated measures confidence intervals based on the MSE for the Problem Type $\times$ Practice Set $\times$ Block interaction. Although participants' median RTs for this analysis were based on only four trials per cell, the very low variability for these problems, together with relatively large samples, provided very good precision of measurement. 
As would be expected given the results of the preceding analysis, there was a main effect of block in which Block 2 had faster mean RT $(660 \mathrm{~ms})$ than Block $1(716 \mathrm{~ms})[F$ $\left.=44.05, p<.001, M S E=10285.69, \eta_{\mathrm{p}}^{2}=.39\right]$. Zeroproblems had a faster mean RT $(671 \mathrm{~ms})$ than 1-problems (707 ms) $\left[F=21.07, p<.001, M S E=8625.56, \eta_{\mathrm{p}}^{2}=.23\right]$, but an Operation $\times$ Problem type interaction occurred $[F=53.10$, $\left.p<.001, M S E=8625.56, \eta_{\mathrm{p}}^{2}=.43\right]$ because multiplication problems were faster for 1-times problems than 0-times problems $(21 \mathrm{~ms})$, whereas addition problems were substantially slower for 1-plus problems than 0-plus problems (-92 ms) (see also Campbell \& Therriault, 2013). The Problem type $\times$ Practice Set interaction $\left[F=4.52, p=.04, M S E=4926.60, \eta_{\mathrm{p}}^{2}\right.$ $=.06]$ reflected a RIF effect for 1-problems [21 ms, $t(71)$ $=2.16, p=.03, \mathrm{SE}=9.83]$ but not for 0-problems $(-4 \mathrm{~ms})$. As Fig. 4 shows, however, the RIF effect for 1-problems originated entirely with the $1 \times \mathrm{N}$ multiplication condition. Specifically, $1 \times \mathrm{N}$ problems presented a 37-ms RIF effect $\left[t(35)=2.88, p=.007, \mathrm{SE}=12.7, \eta^{2}=.19\right]$, whereas $1+\mathrm{N}$ presented a non-significant 6 -ms difference $[t(35)=0.39, p=$ $\left..70, \mathrm{SE}=13.9, \eta^{2}=.004\right]$.

As the RIF effect for $1 \times \mathrm{N}$ is a new finding we conducted a separate test of rule-based multiplication problems, which confirmed a Problem type $(0 \times \mathrm{N}$ vs. $1 \times \mathrm{N}) \times$ Practice Set interaction owing to RIF for $1 \times \mathrm{N}$ but not $0 \times \mathrm{N}[F(1,35)$ $\left.=4.33, p=.05, M S E=6627.05, \eta_{\mathrm{p}}^{2}=.11\right]$. The RIF effect for 1 $\times \mathrm{N}$ was significant both in Block 1 [43 ms, $t(35)=2.65, p=$ $\left..01, \mathrm{SE}=16.3, \eta^{2}=.17\right]$ and Block $2[30 \mathrm{~ms}, t(35)=2.06, p=$ $\left..05, \mathrm{SE}=14.6, \eta^{2}=.11\right]$. A BIC-based Bayesian hypothesis test of the overall $37 \mathrm{~ms}$ RIF effect $(\mathrm{SE}=12.69)$ for $1 \times \mathrm{N}$ problems yielded a Bayes Factor of .129, which indicates that the data provided substantial evidence for the effect. Thus, the identity rule for multiplication proved to be the RIF exception

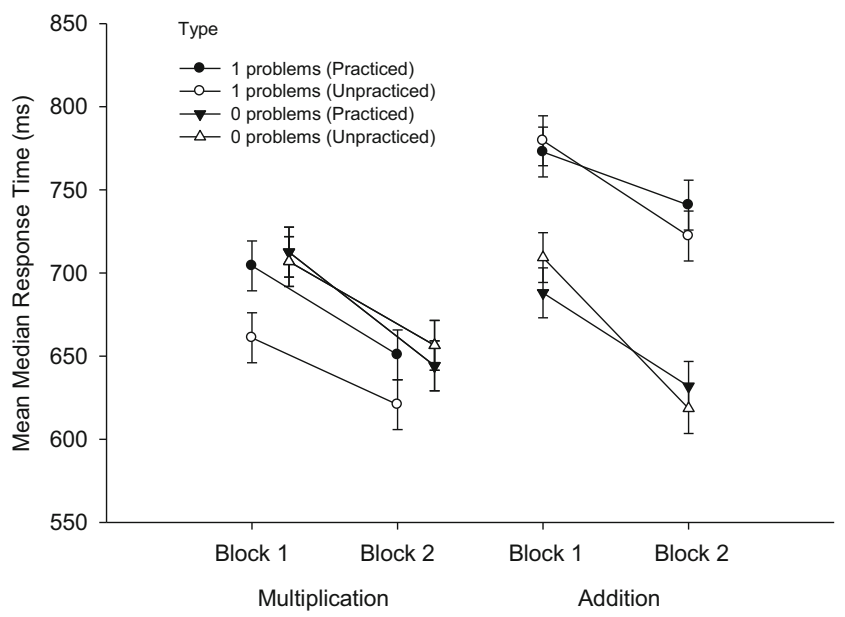

Fig. 4 Mean multiplication and addition response time for 0 and 1 problems during the test phase. Error bars are $95 \%$ repeated-measures confidence intervals based on the MSE for the Problem type $\times$ Practice Set $\times$ Block interaction among the rule-related addition and multiplication problems. Before considering possible explanations for this finding it is important to examine generalization effects for the rule-related problems in the test phase. Generalization (i.e., positive transfer of practice across different items) is expected for rulebased but not fact-based processing.

Generalization of practice The following analysis examined generalization of practice for the rule-related problems by comparing RT for the first four instances versus the second four different instances of each problem type within the first test block. We conducted this sub-block analysis on the test phase data, rather than the practice phase data, because the test phase data allow us to examine generalization effects in the same trials analyzed for RIF effects. Additionally, at the beginning of the practice phase, participants might show a general speed-up across all problems types as they gain confidence in their ability to respond very quickly but accurately (Pirolli \& Anderson, 1985). We expect generalization of practice (i.e., speed-up across sub-blocks) for problems that are solved using a common procedure whereas performance based on retrieval of individual facts should not display generalization. We used the nominally rule-related (but not rulebased) $1+\mathrm{N}$ problems to represent individual-fact problems because they were similar in mean RT to the other 0 and 1 problems and therefore would provide a similar opportunity for speed-up owing to generalization. Previously, both Campbell and Beech (2014) and Campbell and Therriault (2013) found no generalization of practice among $1+$ N problems, suggesting that they were retrieved as individuals facts.

Figure 5 presents mean median RT by operation (multiplication vs. addition), problem Type (0 vs. 1) and sub-block (1 vs. 2). The corresponding ANOVA indicated a three-way interaction $\left[F=6.98, p=.01, \mathrm{MSE}=4434.88, \eta_{\mathrm{p}}^{2}=.09\right]$. As

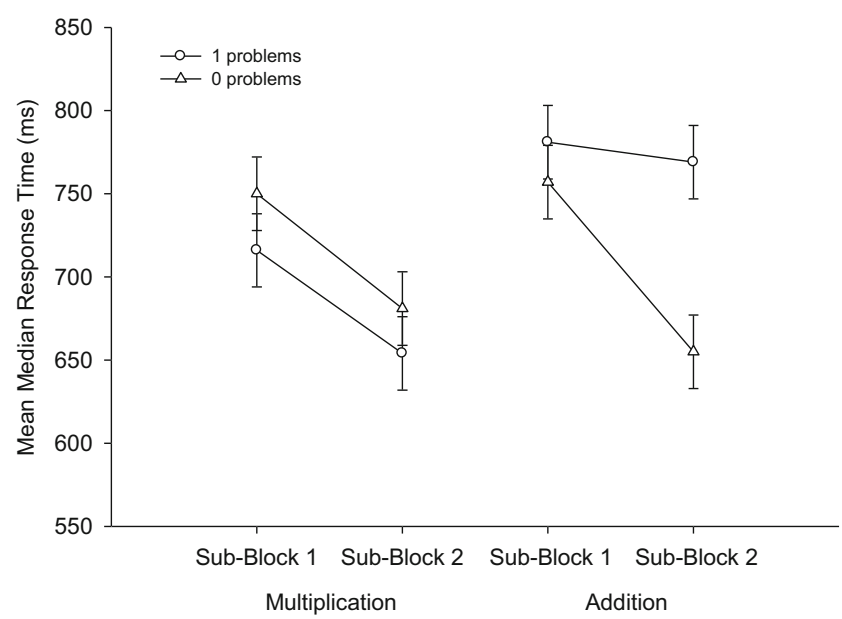

Fig. 5 Mean multiplication and addition response time during Block 1 of the test phase by sub-blocks for the rule-related problems sets. Error bars are $95 \%$ repeated-measures confidence intervals based on the MSE for the Operation $\times$ Problem type $\times$ Sub-block interaction 
Fig. 5 shows, this occurred because both rule-based multiplication problem types $(0 \times \mathrm{N}$ and $1 \times \mathrm{N})$ and the rule-based $0+$ $\mathrm{N}$ additions showed robust speed-up across sub-blocks, but the non-rule-based $1+\mathrm{N}$ addition problems did not. Specifically, mean speed-up across sub-blocks was $69 \mathrm{~ms}$ for $0 \times \mathrm{N}$ $[t(35)=4.2, p<.001, \mathrm{SE}=16.6], 62 \mathrm{~ms}$ for $1 \times \mathrm{N}[t(35)=3.5, p$ $=.001, \mathrm{SE}=17.9], 102 \mathrm{~ms}$ for $0+\mathrm{N}[t(35)=5.49, p<.001, \mathrm{SE}$ $=18.6]$, whereas $1+\mathrm{N}$ problems presented a non-significant 12 -ms difference between sub-blocks $[t(35)=0.67, p=.51, \mathrm{SE}$ $=18.1]$.

Perhaps some part of the speed-up across sub-blocks for 0 $+\mathrm{N}, 0 \times \mathrm{N}$ and $1 \times \mathrm{N}$ problems in Fig. 5 reflected recovery from interference owing to counterpart practice during the practice phase. The same pattern of results held, however, when only the counterpart-unpracticed items were included in the analysis $[F(1,63)=8.18, p=.006, \mathrm{MSE}=150150.15$, $\eta_{\mathrm{p}}^{2}=.12$ for the three-way interaction. ${ }^{3}$ For the counterpartunpracticed problems, mean speed-up across sub-blocks was $70 \mathrm{~ms}$ for $0 \times \mathrm{N}[t(34)=2.82, p=.008, \mathrm{SE}=24.7], 68 \mathrm{~ms}$ for 1 $\times \mathrm{N}[t(32)=2.98, p=.005, \mathrm{SE}=22.7], 183 \mathrm{~ms}$ for $0+\mathrm{N}[t(32)$ $=4.29, p<.001, \mathrm{SE}=42.7]$, and the $1+\mathrm{N}$ problem were $3 \mathrm{~ms}$ slower on average in the second sub-block. As these items were the control condition for which operation-counterparts were not practiced, the speed-up across sub-blocks for these rule-governed problems cannot reflect recovery from itemspecific interference created during the practice phase. These results confirm generalization for $0+\mathrm{N}$ but not $1+\mathrm{N}$ (see also Campbell \& Beech, 2014; Campbell \& Therriault, 2013) and extend the evidence for procedure-based generalization to the identity rules of multiplication. The corresponding analysis of the other fact-based problems indicated no generalization (i.e., speed-up across sub-blocks in Block 1) for either fact-based addition [mean slowing of $-13 \mathrm{~ms}, t(35)=-0.53, p=.60$, SE $=23.8]$ or multiplication [ $4 \mathrm{~ms}, t(35)=0.14, p=.89, \mathrm{SE}=26.2]$.

\section{Discussion}

Campbell and Thompson (2012a; Campbell \& Dowd, 2012; Campbell \& Therriault, 2013) proposed that item-specific RIF of arithmetic facts is competition dependent and reflects active inhibition of the competitor item below pre-RIF baseline rather than, for example, retrieval blocking by strengthened cue-target associations. There is also support for the competitor-inhibition theory in the general RIF literature (Storm \& Levy, 2012). The present RIF findings for $1 \times \mathrm{N}$ problems, however, cannot be explained by item-level

\footnotetext{
${ }_{3}^{3}$ Seven participants with empty cells were excluded from this ANOVA. Given randomized trial order, the first four or second four trials for each problem type within the block could be composed entirely of counterpart practiced or unpracticed items, leaving the other cell empty in this analysis of counterpart-unpracticed problems.
}

competitor inhibition. The generalization results for $1 \times \mathrm{N}$ indicated that participants retrieved an item-general procedure used for all $1 \times \mathrm{N}$ instances. This implies that there would not be item-specific representations of distinct instances of the rule (such as $1 \times 2=2,1 \times 4=4$, etc.) stored in long-term memory. Answering $1+\mathrm{N}$ problems during the practice phase therefore would not encounter competition from individual 1 $\times \mathrm{N}$ counterparts. Therefore, the item-specific RIF for $1 \times \mathrm{N}$ occurred in the absence of item-level competition. Furthermore, inhibitory RIF is assumed to be recruited specifically in response to item-level competition (Anderson, 2003; Storm \& Levy, 2012); thus, the inhibition theory of RIF would not predict RIF for the $1 \times \mathrm{N}$ problems. Consequently, the itemspecific RIF for $1 \times \mathrm{N}$ must reflect item-specific interference rather than competition-based inhibition. We propose that the practiced $1+\mathrm{N}$ items (e.g., $1+3=4,1+5=6,1+6=7$ ) were individually strengthened during the practice phase and were readily reactivated by the $1 \times \mathrm{N}$ counterpart stimuli (e.g., $1 \times$ $3,1 \times 5,1 \times 6$ ) during the test phase. This cue-based interference blocked initiation of the item-general procedure required for the counterpart problems, producing item-specific RIF for $1 \times N=N$ problems. Such interference would not occur in the reverse direction (i.e., RIF of $1+\mathrm{N}$ ) because practicing the procedure for $1 \times \mathrm{N}$ problems specifically strengthened execution of the item-general procedure rather than strengthen item-specific associations.

The RIF observed for $1 \times \mathrm{N}$ problems is evidence that itemspecific RIF does not necessarily require competition at the item level or item-level inhibition. Does this imply that the RIF observed for non-rule-based problems here, and in numerous previous experiments, also could be due to blocking or interference rather than competitor-dependent inhibition? We think it would be premature to draw this conclusion. Campbell and Thompson (2012a; Campbell et al., 2013) found RIF of small addition problems with sums $\leq 10$ (e.g., 2 $+3,3+4$ ) following practice of multiplication counterparts, whereas larger additions (e.g., $7+8,6+7$ ) did not present RIF. Small arithmetic problems usually have much greater memory strength compared to the larger problems. This suggests competition dependency of the effect because small addition problems would be strong competitors for their multiplication counterparts whereas the large addition problems would not. Furthermore, Campbell and Thompson (see also Campbell \& Phenix, 2009; Maslany \& Campbell, 2013; but see Galfano et al., 2011) showed that the effect, at least for non-ruled-based problems, occurs only following retrieval practice of multiplication facts (repeatedly answering $4 \times 6$ $=$ ?) and not following study practice (reading equations silently and stating the answer; e.g., $4 \times 6=24$ ). The retrieval dependency of RIF supports an inhibitory model of the effect over a model based only on cue-related retrieval interference (Anderson, 2003; Storm \& Levy, 2012). Nonetheless, the item-specific RIF observed for $1 \times \mathrm{N}$ rule-based problems 
provides an existence proof that the effect can occur in the absence of item-level competition.

The experiment also demonstrated robust RIF of small factbased multiplications, and the effect was as large as the RIF effect observed for small fact-based additions (Fig. 2). This confirms that the effect exists for both addition and multiplication fact retrieval and that retrieval-induced interference between the operations is approximately symmetrical. Previous research using several different paradigms has found an asymmetry in interference between addition and multiplication whereby multiplication interferes more with addition than vice versa (see Campbell \& Arbuthnott, 2010, for a review). The present results imply that the asymmetrical interference observed in previous research does not arise from asymmetrical RIF; but why would RIF of addition and multiplication not present the asymmetry demonstrated in other interference paradigms? One consideration is that the asymmetrical effects emerged from paradigms that required participants to select or discriminate between the two operations on each trial (e.g., asymmetrical mixing costs in mixed vs. single-operation blocks; asymmetrical operation switch costs in mixed trials; asymmetrical slowing of verification stimuli with the crossoperation answer). The RIF paradigm used here, however, did not require this type of explicit trial by trial discrimination of the operations, but rather involved blocks of one operation (practice phase) followed by a global switch to the other operation (test phase), which may have avoided asymmetrical interference effects. Our results suggest therefore that asymmetrical interference is not inherent in retrieval from addition and multiplication memory but emerges when task demands require trial by trial operation switching or discrimination.

Finally, the experiment demonstrated for the first time that generalization of practice occurs for items governed by the multiplicative identity principle $(1 \times \mathrm{N}=\mathrm{N})$ and zero-product principle $(0 \times \mathrm{N}=0)$, and also replicated the finding of generalization of practice across different instances of the rule-based $0+\mathrm{N}$ problems, but not fact-based $1+\mathrm{N}$ problems (Campbell \& Beech, 2014).The generalization effects observed selectively for the rule-governed problems strongly supports the hypothesis that these problems were answered by reference to algebraic principles each implemented as a procedure that was shared across items. Conversely, the absence of generalization of practice for $1+\mathrm{N}$ problems argues against the possibility that these items were solved in the present experiment by a common shared procedure. Recently, researchers have proposed that simple addition problems may be solved by automatic counting algorithms, at least in expert performers (Barrouillet \& Thevenot, 2013; Campbell, Chen \& Maslany, 2013; Fayol \& Thevenot, 2012). The absence of generalization for non-zero additions (see also Campbell \& Beech, 2014; Campbell \& Therriault, 2013), especially its absence for $1+\mathrm{N}$, single-increment problems that might be likely candidates for automatic counting, suggests that development of automated procedures for simple addition is not the norm. Instead, development of skilled simple addition generally proceeds from counting-based skills to direct memory retrieval, as a variety of previous research has proposed (e.g., Ashcraft \& Guillaume, 2009; Barrouillet \& Fayol, 1998; Shrager \& Siegler, 1998).

\section{Conclusions}

By including all practice-test combinations of fact-based and rule-based counterpart conditions (Table 1) the experiment filled all the conditions to complete the basic picture for inter-operation RIF in simple addition and multiplication, at least for the population sampled. The results indicated that memory for simple fact-based addition and multiplication was similarly susceptible to item-specific inter-operation RIF. Practicing a procedure does not produce RIF of crossoperation counterpart problems, but the results showed that an item-general process (i.e., the procedure for answering $1 \times$ $\mathrm{N}=\mathrm{N}$ problems) can be subject to item-specific interference from practice of counterpart fact-based problems (i.e., the $1+$ $\mathrm{N}=$ ? problems). The item-specific RIF for $1 \times \mathrm{N}$ must reflect item-specific interference rather than item-level competitor inhibition given that there is no item-level representation of $1 \times \mathrm{N}=\mathrm{N}$ facts in long-term memory. To our knowledge, there is no well developed theory or computer model of cognitive arithmetic (e.g., Campbell, 1995; Lebiere \& Anderson, 1998; Siegler \& Shrager, 1984; Verguts \& Fias, 2005) that predicts or explains any of the RIF findings observed in the present research. These RIF phenomena of arithmetic memory represent an important empirical benchmark for future theory development in cognitive arithmetic.

Acknowledgments This research was supported by a grant from the Natural Sciences and Engineering Research Council of Canada.

\section{References}

Anderson, M. C. (2003). Rethinking interference theory: Executive control and the mechanisms of forgetting. Journal of Memory and Language, 49, 415-445.

Anderson, M. C., Bjork, E. L., \& Bjork, R. A. (1994). Remembering can cause forgetting: Retrieval dynamics in long-term memory. Journal of Experimental Psychology: Learning, Memory, and Cognition, 20 , 1063-1087.

Ashcraft, M. H., \& Guillaume, M. M. (2009). Mathematical cognition and the problem size effect. In B. Ross (Ed.), The psychology of learning and motivation (Vol. 51, pp. 121-151). Burlington: Academic Press.

Barrouillet, P., \& Fayol, M. (1998). From algorithmic computing to direct retrieval: Evidence from number and alphabetical arithmetic in children and adults. Memory \& Cognition, 26, 33-368. 
Barrouillet, P., \& Thevenot, C. (2013). On the problem-size effect in small additions: Can we really discard any counting-based account? Cognition, 128, 35-44.

Butterworth, B., Zorzi, M., Girelli, L., \& Jonkheere, A. R. (2001). Storage and retrieval of addition facts: The role of number comparison. Quarterly Journal of Experimental Psychology, $54,1005-1029$.

Campbell, J. I. D. (1995). Mechanisms of simple addition and multiplication: A modified network-interference theory and simulation. Mathematical Cognition, 1, 121-164.

Campbell, J. I. D., \& Arbuthnott, K. A. (2010). Effects of mixing and cuing simple addition and multiplication. European Journal of Cognitive Psychology, 22, 422-442.

Campbell, J. I. D., \& Beech, L. C. (2014). No generalization of practice for non-zero simple addition. Journal of Experimental Psychology: Learning, Memory, and Cognition, 40(6), 1766-1771. doi:10.1037/ $\mathrm{x} \operatorname{lm} 0000003$

Campbell, J. I. D., Chen, Y., \& Maslany, A. J. (2013). Retrieval-induced forgetting of arithmetic facts across cultures. Journal of Cognitive Psychology, 25, 759-773.

Campbell, J. I. D., \& Dowd, R. R. (2012). Inter-operation transfer in Chinese-English bilinguals' arithmetic. Psychonomic Bulletin and Review, 19, 948-954. doi:10.3758/s13423-012-0277-z

Campbell, J. I. D., \& Metcalfe, A. W. S. (2007). Numeral format and arithmetic rules. European Journal of Cognitive Psychology, 19, 335-355.

Campbell, J. I. D., \& Phenix, T. L. (2009). Target strength and retrievalinduced forgetting in semantic recall. Memory \& Cognition, 37, 65-72.

Campbell, J. I. D., \& Therriault, N. H. (2013). Retrieval-induced forgetting of arithmetic facts but not rules. Journal of Cognitive Psychology, 25, 717-724.

Campbell, J. I. D., \& Thompson, V. A. T. (2012a). Retrieval-induced forgetting of arithmetic facts. Journal of Experimental Psychology: Learning, Memory, and Cognition, 38, 118-129. doi:10.1037/ a0025056

Campbell, J. I. D., \& Thompson, V. A. T. (2012b). MorePower 6.0 for ANOVA with relational confidence intervals and Bayesian analysis. Behavioral Research Methods. Advance online publication. doi: 10. 3758/s13428-012-0186-0

Fayol, M., \& Thevenot, C. (2012). The use of procedural knowledge in simple addition and subtraction problems. Cognition, 123, 392-403. doi:10.1016/j.cognition.2012.02.008

Galfano, G., Penolazzi, B., Fardo, F., Dhooge, E., Angrilli, A., \& Umiltà, C. (2011). Neurophysiological markers of retrieval-induced forgetting in multiplication fact retrieval. Psychophysiology, 48, 16811691. doi:10.1111/j.1469-8986.2011.01267.x

Jakab, E., \& Raaijmakers, J. G. W. (2009). The role of item strength in retrieval-induced forgetting. Journal of Experimental Psychology: Learning, Memory, and Cognition, 35, 607-617. doi:10.1037/ a0015264

Jarmasz, J., \& Hollands, J. G. (2009). Confidence intervals in repeatedmeasures designs: The number of observations principle. Canadian Journal of Experimental Psychology, 63, 124-138.

Jost, K., Beinhoff, U., Hennighausen, E., \& Rösler, F. (2004). Facts, rules and strategies in simple multiplication: Evidence from event-related brain potentials. Cognitive Brain Research, 20, 183-193.
Lebiere, C., \& Anderson, J. R. (1998). Cognitive arithmetic. In J. R. Anderson \& C. Lebiere (Eds.), The Atomic Components of Thought (pp. 297-342). Mahwah, NJ: Lawrence Erlbaum Associates.

LeFevre, J., Bisanz, J., Daley, K. E., Buffone, L., Greenham, S. L., \& Sadesky, G. S. (1996). Multiple routes to solution of single-digit multiplication problems. Journal of Experimental Psychology: General, 125, 284-306.

Levy, B. J., McVeigh, N. D., Marful, A., \& Anderson, M. C. (2007). Inhibiting your native language: The role of retrieval-induced forgetting during second-language acquisition. Psychological Science, $18,29-34$.

Maslany, A. J., \& Campbell, J. I. D. (2013). Failures to replicate hyperretrieval-induced forgetting in arithmetic memory. Canadian Journal of Experimental Psychology, 67, 72-77.

Masson, M. E. J. (2011). A tutorial on a practical Bayesian alternative to null-hypothesis significance testing. Behavioral Research Methods, 43, 679-690. doi:10.3758/s13428-010-0049-5

Masson, M. E. J., \& Loftus, G. R. (2003). Using confidence intervals for graphically based data interpretation. Canadian Journal of Experimental Psychology, 57, 203-220.

Miller, J. (1988). A warning about median reaction time. Journal of Experimental Psychology: Human Perception and Performance, 14, 539-543. doi:10.1037/0096-1523.14.3.539

Miller, K. F., \& Paredes, D. (1990). Starting to add worse: effects of learning to multiply on children's addition. Cognition, 37, 213-242.

Norman, K. A., Newman, E. L., \& Detre, G. (2007). A neural network model of retrieval-induced forgetting. Psychological Review, 114, 887-953

Pesenti, M., Depoorter, N., \& Seron, X. (2000). Non-commutability of the $\mathrm{N}+0$ arithmetical rule: A case study of a dissociated impairment. Cortex, 36, 445-454.

Pirolli, P., \& Anderson, J. R. (1985). The role of practice in fact retrieval. Journal of Experimental Psychology: Learning, Memory, and Cognition, 11, 136-153.

Shrager, J., \& Siegler, R. S. (1998). SCADS: A model of children's strategy choices and strategy discoveries. Psychological Science, 9, 405-410.

Siegler, R. S., \& Shrager, J. (1984). A model of strategy choice. In C. Sophian (Ed.), Origins of cognitive skills (pp. 229-293). Hillsdale, NJ: Erlbaum

Singley, M. K., \& Anderson, J. R. (1989). The Transfer of Cognitive Skill. Cambridge, MA: Harvard University Press.

Sokol, S. M., McCloskey, M., Cohen, N. J., \& Aliminosa, D. (1991). Cognitive representations and processes in arithmetic: Inferences from the performance of brain-damaged subjects. Journal of Experimental Psychology. Learning, Memory, and Cognition, 17, 355-376.

Storm, B. C., \& Levy, B. J. (2012). A progress report on the inhibitory account of retrieval-induced forgetting. Memory \& Cognition, 40, 827-843. doi:10.3758/s13421-012-0211-7

Verguts, T., \& Fias, W. (2005). Interacting neighbours: A connectionist model of retrieval in single-digit multiplication. Memory \& Cognition, 33, 1-16.

Zbrodoff, N. J., \& Logan, G. D. (1986). On the autonomy of mental processes: A case study of arithmetic. Journal of Experimental Psychology: General, 115, 118-130. 